\title{
Modul Herediter atas Aljabar Lintasan Leavitt dari Graf $A_{\infty}$
}

\author{
Delsi Kariman, Irawati, Intan Muchtadi-Alamsyah \\ Kelompok Keahlian Aljabar, Fakultas Matematika dan Ilmu Pengetahuan Alam \\ Institut Teknologi Bandung, Jalan Ganesha 10 Bandung 40132, Indonesia \\ delsikariman79@gmail.com, irawati@math.itb.ac.id, ntan@math.itb.ac.id
}

\begin{abstract}
Abstrak
Misalkan $E$ suatu graf berarah dan $K$ lapangan. Aljabar lintasan Leavitt $L_{K}(E)$ adalah $K$-aljabar lintasan diperluas yang berasosiasi dengan graf $E$ modulo relasi tertentu. Dalam tulisan ini, diselidiki sifat keherediteran modul atas aljabar lintasan Leavitt dari graf garis tak hingga $A_{\infty}$.

Keywords: hereditary module, Leavitt path algebra, infinite line graph
\end{abstract}

\begin{abstract}
Let $E$ be a directed graph and $K$ be a field. The Leavitt path algebra $L_{K}(E)$ is an expanded path $K$-algebra modulo some relations. In this paper, we investigate the hereditary property of the module over the Leavitt path algebra of $A_{\infty}$ infinite line graph.

Kata kunci: modul herediter, aljabar lintasan Leavitt, graf garis tak hingga
\end{abstract}

\section{Pendahuluan}

Modul herediter merupakan perumuman dari gelanggang herediter, pertama kali diperkenalkan oleh Shrikhande [10] pada tahun 1973. Studi tentang modul herediter atas gelanggang telah banyak dilakukan seperti dapat dilihat pada $[5,7]$.

Sifat keherediteran juga muncul pada area teori representasi. Gabriel [6] pada tahun 1972 telah memperkenalkan graf (berarah) dan representasi graf. Setiap graf dapat diasosiasikan dengan aljabar lintasan, dan sebaliknya. Modul atas aljabar lintasan yang berasosiasi dengan suatu graf dapat digambarkan. Gabriel juga membuktikan bahwa jika graf hingga, terhubung dan asiklus maka aljabar lintasan bersifat herediter. Oleh karena itu, dapat disimpulkan bahwa modul atas aljabar lintasan dari graf hingga, terhubung dan asiklus adalah herediter. Yang dan Xu [11] pada tahun 2016 juga telah membuktikan bahwa $A$ aljabar berdimensi hingga bersifat herediter jika dan hanya jika tidak ada loop pada graf yang berasosiasi dengan $A$. Selanjutnya pada tahun 2018, Kariman dkk. [8] menyelidiki sifat keherediteran pada modul atas aljabar lintasan dari graf yang memuat siklus.

Kajian aljabar lintasan berkembang pada aljabar lintasan Leavitt yang merupakan aljabar lintasan diperluas modulo relasi tertentu. Aljabar lintasan Leavitt pertama kali diperkenalkan oleh Abrams dan Aranda Pino [1] pada tahun 2005. Ara dkk. [3] membuktikan isomorfisma monoid graf $E$ dan monoid kelas isomorfisma modul projektif yang dibangun secara hingga atas aljabar lintasan Leavitt $L_{K}(E)$. Selanjutnya Ara dkk. membuktikan bahwa jika graf $E$ hingga maka $L_{K}(E)$ herediter, sehingga modul atas $L_{K}(E)$ dari graf hingga adalah herediter.

2000 Mathematics Subject Classification: 16G30, 16D40

Received: 02-03-2019, accepted: 22-07-2019. 
Muncul pertanyaan bagaimanakah sifat keherediteran modul atas $L_{K}(E)$ dari graf tak hingga. Tulisan ini mengkaji sifat keherediteran modul atas aljabar lintasan Leavitt dari graf garis tak hingga.

\section{Metode Penelitian}

Metodologi penelitian yang dilakukan adalah metode eksplorasi dan adaptasi dari hasilhasil yang sudah ada melalui studi literatur. Sifat keherediteran modul projektif atas aljabar lintasan Leavitt dari graf hingga telah diperoleh dengan menggunakan teorema yang dikemukakan oleh Ara dkk. (2007). Dengan menggunakan teorema yang sama, bisa dicari semua modul projektif atas aljabar lintasan Leavitt dari graf garis tak hingga.

\section{Hasil dan Pembahasan}

Notasi, definisi, dan hasil-hasil penelitian sebelumnya yang digunakan dalam tulisan ini diperkenalkan pada bagian ini. Semua bukti dapat ditemukan pada $[1,2,3,4,9]$.

Suatu graf (berarah) $E=\left(E^{0}, E^{1}, r, s\right)$ terdiri dari dua himpunan $E^{0}, E^{1}$ dan pemetaan $r, s: E^{1} \rightarrow E^{0}$. Unsur $E^{0}$ dinamakan titik dan unsur $E^{1}$ dinamakan sisi atau panah. Titik awal dan titik akhir sebarang sisi $e$ dinotasikan secara berturut-turut sebagai $s(e)$ dan $r(e)$. Jika $s(e)=v$ dan $r(e)=w$, maka dikatakan bahwa $v$ memancarkan (emit) $e$, dan $w$ menerima e. Titik yang tidak memancarkan sisi dinamakan sink. Jika $s^{-1}(v)$ himpunan hingga untuk setiap $v \in E^{0}$, maka graf $E$ disebut graf baris hingga. Fokus graf pada tulisan ini adalah graf baris hingga. Jika $E^{0}$ hingga, dengan hipotesis graf baris hingga maka $E^{1}$ hingga, sehingga graf $E$ hingga. Graf $E$ dikatakan terhubung jika graf yang diperoleh dari $E$ dengan menghilangkan arah pada panah-panahnya adalah graf terhubung.

Lintasan $\mu$ di graf $E$ adalah barisan sisi $\mu=e_{1} \cdots e_{n}$ sehingga $r\left(e_{i}\right)=s\left(e_{i+1}\right)$ untuk $i=1, \cdots, n-1$, dengan $s(\mu)=s\left(e_{1}\right)$ adalah titik awal $\mu, r(\mu)=r\left(e_{n}\right)$ adalah titik akhir $\mu$, dan $n$ adalah panjang $\mu$, yakni, $l(\mu)=n$. Suatu lintasan dengan panjang $l \geqslant 1$ dikatakan siklus jika $s(\mu)=r(\mu)$. Suatu sisi $e$ disebut sisi keluar pada siklus $\mu=e_{1} \cdots e_{n} e_{1}$ jika terdapat titik $i$ sehingga $s(e)=s\left(e_{i}\right)$ dan $e \neq e_{i}$. Suatu graf dikatakan asiklus jika $E$ tidak memuat siklus.

Himpunan lintasan dengan panjang $n \geqslant 2$, dinotasikan dengan $E^{n}$, dan $E^{*}=\cup_{n \geqslant 0} E^{n}$ himpunan semua lintasan. Relasi $\geqslant$ didefinisikan pada $E^{0}$ dengan menetapkan $v \geqslant w$ jika terdapat lintasan $\mu \in E^{*}$ dengan $s(\mu)=v$ dan $r(\mu)=w$. Himpunan $T(v)=\left\{w \in E^{0} \mid v \geqslant w\right\}$ dinamakan tree dari $v$.

Misalkan $K$ lapangan dan $E$ sebarang graf, aljabar lintasan $K E$ didefinisikan sebagai $K$-aljabar bebas dengan basis lintasan-lintasan di $E$ dan memenuhi relasi:

(1) $v_{i} v_{j}=\delta_{i j} v_{i}$ untuk setiap $v_{i}, v_{j} \in E^{0}$.

(2) $e_{i}=e_{i} r\left(e_{i}\right)=s\left(e_{i}\right) e_{i}$ untuk setiap $e_{i} \in E^{1}$.

Ideal dua sisi dari aljabar lintasan $K E$ yang dibangun oleh panah-panah di $E$ dinamakan ideal panah dari $K E$ dan ditulis $R_{E}$. Ideal dua sisi $I$ dari $K E$ dikatakan admissible jika terdapat $m \geqslant 2$ sehingga $R_{E}^{m} \subseteq I \subseteq R_{E}^{2}$. Jika $I$ ideal admissible dari $K E$ maka $(E, I)$ dinamakan graf terbatas. Aljabar kuosien $K E / I$ dinamakan aljabar graf terbatas.

Selanjutnya diperkenalkan definisi aljabar lintasan herediter dan modul herediter.

Definisi 3.1. Aljabar A dikatakan herediter kiri jika setiap ideal kiri dari A adalah modul projektif.

Definisi 3.2. Misalkan $R$ sebarang ring. Suatu $R$-modul $M$ dikatakan herediter jika semua submodul $M$ adalah projektif.

Karakterisasi dari aljabar lintasan herediter diberikan pada dua teorema berikut.

Teorema 3.3. Jika E graf hingga, terhubung, dan asiklus, maka aljabar KE adalah aljabar herediter. 
BuKTi. Lihat $[4]$

Teorema 3.4. Misalkan A aljabar. Maka kondisi berikut ekivalen:

(a) A herediter kiri

(b) Setiap submodul dari A-modul kiri projektif adalah projektif

(c) Setiap submodul dari A-modul kiri projektif dibangun secara hingga adalah projektif

BukTi. Lihat $[4]$

Aljabar lintasan Leavitt merupakan aljabar lintasan diperluas yang memenuhi relasi tertentu. Pertama dibutuhkan konsep graf perluasan. Diberikan graf $E$, graf $E$ dapat diperluas dengan memandang arah sebaliknya dari sisi-sisi dalam $E^{1}$. Sisi dalam $E^{1}$ disebut sisi nyata dan sisi dengan arah berlawanan dari sisi nyata disebut sisi hantu. Himpunan sisi hantu dalam $E$ dinotasikan dengan $\left(E^{1}\right)^{*}$. Graf perluasan $E$ adalah graf baru $\hat{E}=\left(E^{0}, E^{1} \cup\left(E^{1}\right)^{*}, r^{\prime}, s^{\prime}\right)$ dengan $\left(E^{1}\right)^{*}=\left\{e_{i}^{*} \mid e_{i} \in E^{1}\right\}$ dan fungsi $r^{\prime}$ dan $s^{\prime}$ didefinisikan sebagai $\left.r^{\prime}\right|_{E^{1}}=r,\left.s^{\prime}\right|_{E^{1}}=$ $s, r^{\prime}\left(e_{i}^{*}\right)=s\left(e_{i}\right)$, dan $s^{\prime}\left(e_{i}^{*}\right)=r\left(e_{i}\right)$. Gambar 1 merupakan contoh dari graf perluasan.

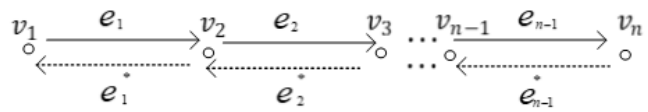

Gambar 1. Graf perluasan

Definisi 3.5. Misalkan E graf baris hingga. Aljabar lintasan Leavitt $L_{K}(E)$ didefinisikan sebagai $K$-aljabar lintasan atas graf perluasan $\hat{E}$ dengan relasi:

(CK1) $e^{*} f=\delta_{\text {ef }} r(e)$ untuk setiap $e, f \in E^{1}$

(CK2) $v=\Sigma_{\left\{e \in E^{1} \mid s(e)=v\right\}} e e^{*}$ untuk setiap $v \in E^{0}$ bukan sink.

Syarat (CK1) dan (CK2) disebut relasi Cuntz-Krieger. Khususnya syarat (CK2) relasi Cuntz-Krieger di $v_{i}$. Jika $v_{i}$ sink, maka tidak dimiliki syarat (CK2) di $v_{i}$.

Selanjutnya diselidiki syarat pada titik $v \in E^{0}$ sedemikian sehingga $L_{K}(E) v$ ideal kiri minimal, atau secara ekivalen dikatakan bahwa $L_{K}(E) v$ modul kiri sederhana. Kajian ini membutuhkan konsep bifurkasi dan line point.

Definisi 3.6. Titik $v \in E^{0}$ dikatakan bifurkasi (atau tidak ada bifurkasi pada v) jika $s^{-1}(v)$ memiliki paling sedikit dua unsur. Titik $u \in E^{0}$ dikatakan line point jika $u$ bukan bifurkasi dan tidak ada siklus pada setiap titik pada $w \in T(u)$. Himpunan semua line point pada $E^{0}$ dinotasikan dengan $P_{l}(E)$.

Teorema 3.7. Misalkan $u \in E^{0}$. Ideal kiri $L_{K}(E) u$ merupakan ideal kiri minimal jika dan hanya jika $u \in P_{l}(E)$.

BukTi. Lihat [2]

Sekarang diperkenalkan isomorfisma monoid graf $E$ dan monoid kelas isomorfisma modul projektif atas $L_{K}(E)$ yang dibangun secara hingga. Pertama dibutuhkan dua definisi berikut.

Definisi 3.8. Misalkan E sebarang graf. Monoid komutatif bebas pada himpunan pembangun $\left\{a_{v} \mid v \in E^{0}\right\}$ dinotasikan dengan $M_{E}$, modulo relasi diberikan oleh

$$
a_{v}=\Sigma_{\{e \in E \mid s(e)=v\}} a_{r(e)}
$$

untuk setiap $v$ yang bukan sink atau memancarkan tak hingga sisi. 
Definisi 3.9. Misalkan $L_{K}(E)$ aljabar lintasan Leavitt. Himpunan kelas isomorfisma $L_{K}(E)$ modul kiri projektif yang dibangun secara hingga dinotasikan dengan $V\left(L_{K}(E)\right)$. Himpunan $V\left(L_{K}(E)\right)$ adalah monoid komutatif dengan mendefinisikan

untuk $[P],[Q] \in V\left(L_{K}(E)\right)$.

$$
[P]+[Q]:=[P \oplus Q]
$$

Teorema 3.10. Misalkan E graf baris hingga, maka terdapat isomorfisma monoid

$$
V\left(L_{K}(E)\right) \cong M_{E}
$$

Lebih lanjut, jika E hingga maka $L_{K}(E)$ herediter.

BukTi. Lihat [3]

Selanjutnya diselidiki sifat keherediteran modul atas aljabar lintasan Leavitt. Sebelumnya diingat kembali hasil-hasil yang sudah diperoleh pada penelitian sebelumnya [8], yaitu modul herediter atas aljabar lintasan.

Jika $E$ graf hingga, terhubung, dan asiklus maka berdasarkan Teorema 3.3 aljabar lintasan $K E$ herediter. Artinya, semua modul projektif atas $K E$ dari graf hingga, terhubung, dan asiklus adalah herediter.

Teorema 3.11. Misalkan $E$ graf siklus dengan $n$ titik, I ideal dari aljabar lintasan $K E$ yang dibangun oleh lintasan-lintasan panjang $m+1$ dan $N_{n}^{m}=K E / I$ aljabar lintasan Nakayama self-injective. Semua modul projektif atas $N_{n}^{m}$ bukan herediter.

BukTi. Lihat [8]

Teorema 3.12. Misalkan E graf yang merupakan gabungan beberapa siklus dan pohon. Misalkan $S_{1}, \cdots, S_{k}$ siklus-siklus di $E$ dan $A=K E / I$ aljabar lintasan dengan $I$ ideal yang dibangun oleh lintasan-lintasan di siklus $S_{1}, \cdots, S_{k}$ dengan panjang $m_{1+1}, \cdots, m_{k+1}$, secara berturut-turut.

(a) Semua A-modul projektif di titik-titik yang berada pada siklus dan lintasan berarah dengan arah sama yang memiliki titik ujung pada siklus bukanlah herediter;

(b) Modul projektif di titik-titik yang berada pada pohon (selain titik-titik yang berada lintasan berarah dengan arah sama yang memiliki titik ujung pada siklus) adalah herediter;

(c) Modul projektif di titik akhir sisi keluar pada siklus adalah herediter.

BukTI. Lihat $[8]$ 
Contoh 3.13. Pada Gambar 2, modul herediter adalah modul projektif yang bersesuaian dengan titik-titik yang berada pada daerah yang diarsir.

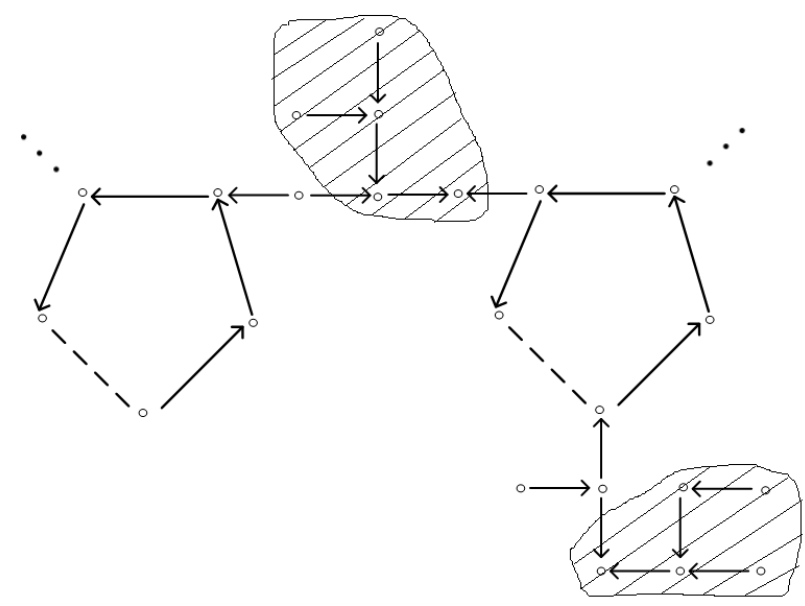

GAmBAR 2. Graf yang memuat siklus dan pohon

Selanjutnya diselidiki sifat keherediteran modul atas aljabar lintasan Leavitt $L_{K}(E)$. Berdasarkan Teorema 3.10, aljabar lintasan Leavitt $L_{K}(E)$ pada graf hingga $E$ adalah herediter, sehingga semua modul projektif atas $L_{K}(E)$ dari graf hingga adalah herediter.

Hasil utama tulisan ini adalah sifat keherediteran modul atas $L_{K}(E)$ untuk graf garis tak hingga yang diberikan pada teorema berikut.

Teorema 3.14. Misalkan $A_{\infty}$ (lihat Gambar 3) merupakan graf garis tak hingga dan $L_{K}\left(A_{\infty}\right)$ aljabar lintasan Leavitt. Semua modul projektif atas $L_{K}\left(A_{\infty}\right)$ adalah herediter.

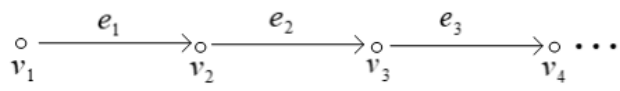

Gambar 3. Graf garis tak hingga

BukTI. Misalkan $A_{\infty}$ graf garis tak hingga seperti dapat dilihat pada Gambar 3. Menurut Definisi 3.8, diperoleh relasi $a_{v_{1}}=a_{v_{2}}=a_{v_{3}}=\cdots$, sehingga diperoleh

$$
M_{A_{\infty}}=\left\langle a_{v_{1}}\right\rangle=\left\{0, a_{v_{1}}, 2 a_{v_{1}}, \cdots\right\} \cong Z^{+}
$$

Graf $A_{\infty}$ adalah graf baris hingga, Teorema 3.10 dapat digunakan untuk memperoleh

$$
V\left(L_{K}\left(A_{\infty}\right)\right)=\left\{0, L_{K}\left(A_{\infty}\right) v_{1}, L_{K}\left(A_{\infty}\right) v_{1} \oplus L_{K}\left(A_{\infty}\right) v_{1}, \cdots\right\}
$$

Titik $v_{1}$ bukan bifurkasi dan tidak ada siklus pada setiap titik di $T\left(v_{1}\right)$ sehingga berdasarkan Definisi 3.6, $v_{1}$ adalah line point. Berdasarkan Teorema 3.7, diperoleh bahwa $L_{K}\left(A_{\infty}\right) v_{1}$ adalah ideal kiri minimal, dengan kata lain $L_{K}\left(A_{\infty}\right) v_{1}$ adalah modul kiri sederhana atas $L_{K}\left(A_{\infty}\right)$. Oleh karena itu, dapat disimpulkan bahwa semua modul projektif atas $L_{K}\left(A_{\infty}\right)$ adalah herediter.

\section{Simpulan}

Dari hasil penelitian diperoleh bahwa semua modul projektif atas aljabar lintasan Leavitt dari graf garis tak hingga adalah herediter. 


\section{DAFtar Pustaka}

[1] Abrams, G., and Aranda Pino, G., 2005, The Leavitt path algebra of a graph, Journal of Algebra, Volume 293, Issue 2, Pages 319-334.

[2] Aranda Pino, G., Martin Barquero, D., Martin Gonzalez, C., and Siles Molina, M., 2008, The socle of a Leavitt path algebra, Journal of Pure and Applied Algebra, Volume 212, Issue 2, Pages 500-509.

[3] Ara, P., Moreno, M.A, and Pardo, E., Nonstable K-theory for Graph Algebras J. Pure Appl. Algebra, Volume 212, Issue 3, Pages 157-178.

[4] Assem, I., Simson, D., and Skowronski, A., 2006, Elements of the Representattion Theory of Associative Algebra, Cambridge University Press, USA.

[5] Dinh, H. Q., Guil, A. P. A., and Lopez-Permouth, S. R., 2006, On the Goldie Dimension of Rings and Modules, J. Algebra, Volume 305, Issue 2, Pages 937-948.

[6] Gabriel, P., 1972, Unzerlegbare Darstellungen I, Manuscripta Math, Volume 6, Pages 71-103.

[7] Hill, Endomorphism Rings of Hereditary Modules, 1977, Arch. Mathematics, Volume 28, Issue 1, Pages 45-50.

[8] Kariman, D., Muchtadi-Alamsyah, I., Irawati, Hereditary Modules over Path Algebras of a Graph Containing Cycles, Submitted.

[9] Passman, D.S., 1991, A Course In Ring Theory, Brooks/Cole Publishing Company, California.

[10] Shrikhande, M.S., On Hereditary and Cohereditary Modules, 1973, Can. J. Math, Volume 25, Pages 892896.

[11] Yang, Y., and Xu, J., 2016, A New Characterization of Hereditary Algebras, Communication of Algebra, Volume 44, Issue 10, Pages 4196-4199. 